\title{
Neuropsychological and quantitative oculometric study of a case of sporadic Creutzfeldt-Jakob disease at predementia stage
}

\author{
M Zarei, S A R Nouraei, D Caine, J R Hodges, R H S Carpenter
}

J Neurol Neurosurg Psychiatry 2002;73:56-58

A quantitative assessment of eye movements and a detailed neuropsychological profile were conducted at predementia stage in a patient who later had histological confirmation of sporadic Creutzfeldt-Jakob disease (CJD). The patient was a middle aged man who presented with abnormal eye movements and poor balance. Neuropsychological deficits suggested orbito-mesial dysfunction, resembling progressive supranuclear palsy. Oculometry showed accurate but dramatically slowed saccades, with normal pursuit movements. Neuropsychology and quantitative oculometry may be of value in the differential diagnosis and earlier detection of dementia-akinetic-rigid syndromes; in particular, because of the highly stereotyped nature of saccades, routine quantitative oculometry can reveal significant impairment at a very early stage in some cases and could thus facilitate earlier diagnosis.

\footnotetext{
C
} reutzfeldt-Jakob Disease (CJD) is a fatal prion disease characterised by spongiform changes in brain tissue, neural loss and astrocytic reactions, ${ }^{1}$ and a rapidly progressive dementia. To our knowledge this report is the first quantitative oculometric study of a patient with CJD at predemential stage. Abnormal eye movements are rarely the main presenting complaint in prion diseases; they are usually found at the later stages, when dementia and other neurological signs are evident, ${ }^{2}$ and secondary to cerebellar ${ }^{3}$ and vestibular $^{4}$ involvement. The pattern of dementia in CJD has not been extensively studied, largely because of practical difficulties in performing neuropsychological assessments on mentally debilitated patients. Early symptoms-such as deficits in concentration, memory, and problem solving, apathia, labile emotions, asthenia, altered sleep patterns and appetite, weight loss, and loss of libido-are non-specific and can be readily attributed to depression, for which extensive neuropsychological assessment is rarely indicated. In the present study both quantitative oculometry and neuropsychological assessment were carried out before the emergence of cognitive symptoms, shedding light on early patterns of impairment in CJD and raising the hope of earlier diagnosis. As well as obvious implications in terms of planning care and handling bodily fluids, specimens and tissues, there is potential therapeutic benefit, as emerging neuroprotective drugs for slowing neurodegeneration require an early diagnosis for early treatment to be instituted.

\section{CASE REPORT}

A 55 year old non-smoking man, a previously healthy company manager, presented with progressive difficulty in maintaining balance and tracking moving objects, and diplopia for distant targets. There were no sensory, motor, or cogni-

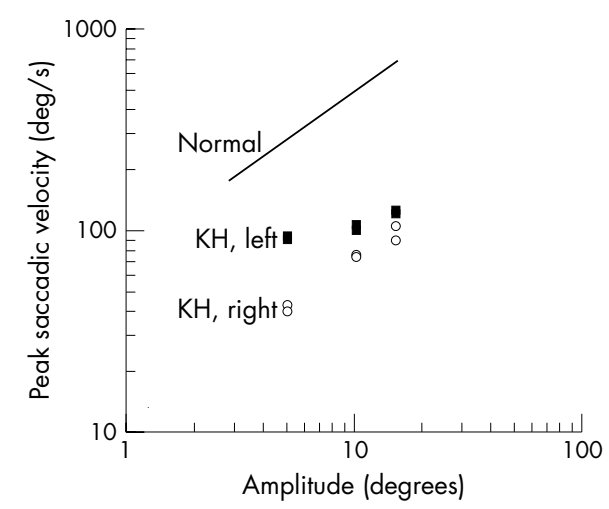

Figure 1 Peak saccadic velocity as a function of amplitude, for movements in the two directions. The line shows a typical normal human velocity-amplitude relation.

tive symptoms. Physical examination on admission was unremarkable and the Addenbrooke's cognitive examination score $^{5}$ was normal (97/100), with no frontal lobe release or cortical signs. He had facial hypomimia with mild rigidity in the right upper limb, and was also bilaterally ataxic with dysdiadokokinesia: his gait was unsteady with poor postural reflexes. Saccades appeared sluggish while ocular pursuit and oculo-cephalic reflexes were intact. Haematological, biochemical, and immunological tests-including paraneoplastic markers, serum caeruloplasmin, autoimmune profile, serology for Whipple's disease, and routine cerebrospinal fluid (CSF) examination-were all normal, as was neuroimaging (magnetic resonance imaging and single photon emission computed tomography).

In view of the unusual eye movements, the oculomotor system was examined quantitatively within days of presentation, using an infrared oculometer, ${ }^{6}$ with the head immobilised on a bite bar and appropriate visual stimuli presented at a distance of $57 \mathrm{~cm}$. Visually evoked saccades and OKN quick phases were dramatically slowed to around $12 \%$ of typical normal values. Leftward saccades were significantly faster than rightward $(\mathrm{p}<0.02)$, and their latencies were higher but not abnormal (mean (SEM): 231 (6) $v 181$ (14) ms; p < 0.01). The relation between peak saccadic velocity and amplitude (fig 1) was similar to that of a normal subject, albeit with much lower velocity values. Neither smooth pursuit nor slow phases of optokinetic nystagmus were affected, and there was no obvious abnormality of the accuracy of saccades in either direction.

To assess any subclinical cognitive impairment, we carried out an extensive neuropsychological assessment of memory, attention, language, visuoperceptual function, and executive ability (table 1). General intellectual function, attention, naming, visual perception, and recall of stories and designs were all 
Table 1 Results of neuropsychological examination

\begin{tabular}{|c|c|c|}
\hline Test & $\begin{array}{l}\text { Age scaled } \\
\text { scores }\end{array}$ & $\begin{array}{l}\text { Age matched control } \\
\text { scores or patient's } \\
\text { centile }\end{array}$ \\
\hline \multicolumn{3}{|c|}{ General intellectual function (WAIS-R) } \\
\hline Picture completion & \multicolumn{2}{|l|}{13} \\
\hline Digit span & \multicolumn{2}{|l|}{12} \\
\hline Block design & \multicolumn{2}{|l|}{14} \\
\hline Arithmetic & \multicolumn{2}{|l|}{11} \\
\hline Similarities & \multicolumn{2}{|l|}{13} \\
\hline *Digit symbol substitution & \multicolumn{2}{|l|}{9} \\
\hline \multicolumn{3}{|l|}{ Memory } \\
\hline \multicolumn{3}{|l|}{ Logical memory (WMS-R) } \\
\hline Immediate & 26 & (67th centile) \\
\hline Delayed & 24 & (79th centile) \\
\hline \multicolumn{3}{|c|}{ Visual reproduction (WMS-R) } \\
\hline Immediate & 40 & (99th centile) \\
\hline Delayed & 30 & (74th centile) \\
\hline \multicolumn{3}{|c|}{ Rey auditory verbal learning test } \\
\hline Total 5 trials & 38 & $47.6(8.5)$ \\
\hline * Recall list $A$ & 8 & $9.6(2.9)$ \\
\hline *20 Min delayed recall list & 6 & $10(2.6)$ \\
\hline \multicolumn{3}{|l|}{ A } \\
\hline Recognition list $\mathrm{A}$ & 15 & $13.9(0.9)$ \\
\hline \multicolumn{3}{|l|}{ Rey complex figure test } \\
\hline Copy & 36 & $35.6(0.8)$ \\
\hline 30 Min delayed recall & 24 & $18.8(7.4)$ \\
\hline \multicolumn{3}{|l|}{ Executive function } \\
\hline \multicolumn{3}{|l|}{ *Trail making test } \\
\hline Part A & $60 \mathrm{~s}$ & (10th to 25 th centile) \\
\hline Part B & $115 \mathrm{~s}$ & (25th to 50th centile) \\
\hline *Letter fluency (FAS) & 31 & (19th centile) \\
\hline $\begin{array}{l}\text { *Wisconsin card sorting test } \\
\text { (WCST) }\end{array}$ & 3 categories & $5.6(1.1)$ \\
\hline \multicolumn{3}{|l|}{ Language } \\
\hline Graded naming test & 22 & (50th centile) \\
\hline \multicolumn{3}{|c|}{$\begin{array}{l}\text { Control values are mean (SD). } \\
\text { *Tests on which performance was considered abnormal. Published } \\
\text { norms used for comparisons. } \\
\text { WAIS-R, Wechsler adult intelligence scale-revised; WMS-R, Wechsler } \\
\text { memory scale-revised. }\end{array}$} \\
\hline
\end{tabular}

intact, but retrieval of unstructured verbal information was impaired in comparison with recognition memory, with deficits on several specific tests of executive ability, including completion of only three of six categories on the Wisconsin card sorting test. Psychomotor speed was reduced.

Rapid deterioration raised the possibility of CJD, and examination of CSF showed very high titres of S-100b $(5.92 \mathrm{ng} / \mathrm{ml} v$ less than 0.38 in normal cases), neurone specific enolase ( 310 $\mathrm{ng} / \mathrm{ml} v$ less than 20 ), and 14-3-3 proteins. These made CJD a very likely diagnosis. Towards the end, the patient developed fasciculations and myoclonic jerks, became verbally unresponsive, and died of bronchopneumonia six months after presentation. Necropsy examination confirmed the diagnosis of sporadic CJD, with a diffuse pattern of lesions involving many areas of the brain including the brain stem, and no clear focus of degeneration.

\section{DISCUSSION}

These findings emphasise the importance of considering CJD in the differential diagnosis of progressive supranuclear palsy, from which it is at times differentiated by a "wait and see" policy because unlike other dementia-akinetic-rigid syndromes such as corticobasal degeneration and multisystem atrophy, CJD progresses much more rapidly and death ensues within a few months. Neuropsychological assessment in progressive supranuclear palsy shows deficits of attention, executive function, memory retrieval, visual and auditory perception, and language production. ${ }^{3}$ In this case, however, early neuropsychological impairment was limited to an executive deficit, although it was followed by further cognitive impairment which we were unable to assess fully at later stages of the disease. Interestingly, in progressive supranuclear palsy, there is a strong correlation between abnormal eye movements and neuropsychological deficit, particularly in sustained and divided attention. ${ }^{8}$ It is yet to be shown whether abnormal oculometry in other dementia-akinetic-rigid syndromes is also correlated with the severity of cognitive impairment. A study of the eye movements of 23 patients with akinetic-rigid syndrome (idiopathic Parkinson's disease, multisystem atrophy, pure akinesia, progressive supranuclear palsy, and corticobasal degeneration) showed that, though impairment of pursuit movement was a common finding and could not differentiate between subgroups, only those with corticobasal degeneration showed prolonged saccadic latency, and only patients with progressive supranuclear palsy had slowed saccades. ${ }^{9}$ This suggests that quantitative oculometry may be useful in the routine assessment of such patients. The oculomotor control system has a wide anatomical distribution and is composed of numerous different cell types. Many neurological diseases therefore leave characteristic signatures on its performance, as they damage different and sometimes selective parts of its widely distributed neural circuitry. ${ }^{10}$

We believe that the pattern of neuropsychological impairment and quantitative oculometric abnormalities described in this paper may be useful in the early diagnosis of CJD. In particular, as saccades are highly stereotypic and can be recorded easily, consistently, non-invasively, and precisely, with appropriate quantitative analysis, relatively small deviations from normality can be very significant and have high diagnostic value, if specific patterns of impairment are demonstrated for different diseases. At the time the oculometry was performed in our patient the saccadic slowing was already dramatic; it seems probable that significant slowing, probably indiscernible without quantitative examination, would have been found had we made the measurements some months earlier. Given the very low incidence of CJD, the chances of making quantitative eye movement measurements in a patient before the diagnosis is clear are necessarily small, and previous reports of saccadic slowing have been at a relatively late stage in the disease. ${ }^{11}$

We were fortunate in having the opportunity to make these measurements at such an early stage, quantitative oculometry not being a routine neurological procedure. We hope that as a result of our serendipitous discovery, others will be encouraged to undertake speculative quantitative oculometry in similar circumstances.

\section{ACKNOWLEDGEMENTS}

We would like to thank Dr Siddharthan Chandran, Dr Thomas H Bak, and Dr Christopher M C Allen for their contributions in patient care.

\section{Authors' affiliations}

M Zarei, D Caine, J R Hodges, Department of Clinical Neurology, Addenbrooke's Hospital, University of Cambridge, Cambridge, UK S A R Nouraei, R H S Carpenter, The Physiological Laboratory, University of Cambridge, Cambridge CB2 3EG, UK

Correspondence to: Dr R H S Carpenter; rhsc1@cam.ac.uk

Received 2 October 2001

In revised form 27 February 2002

Accepted 28 February 2002

\section{REFERENCES}

1 Brown P, Gibbs CJ, Rodgers-Johnson P, et al. Human spongiform encephalopathy: the National Institutes of Health series of 300 cases of experimentally transmitted disease. Ann Neurol 1994;35:513-29.

2 Goldhammer Y, Gabizon R, Meiner Z, et al. An Israeli family with Gerstmann-Straussler-Scheinker disease manifesting the codon 102 mutation in the prion protein gene. Neurology 1993;43:2718-19. 
3 Seno $\mathrm{H}$, Ishino $\mathrm{H}$, Inagaki $\mathrm{T}$, et al. An autopsy case of ataxic form of Creutzfeldt-Jakob disease. No To Shinkei 1992;44:177-81.

4 Walsh T. Neuro-ophthalmology: clinical signs and symptoms. London Williams and Wilkins, 1997.

5 Mathuranath PS, Nestor PJ, Berrios GE, et al. A brief cognitive test battery to differentiate Alzheimer's disease and frontotemporal dementia. Neurology 2000;55:1613-20.

6 Carpenter RHS. Movements of the eyes, 2nd ed. London: Pion, 1988.

7 Bahill AT, Clark MR, Stark L. The main sequence, a tool for studying

human eye movements. Math Biosci 1975;24:191-204.
8 Esmonde T, Giles E, Xuereb J, et al. Progressive supranuclear palsy presenting with dynamic aphasia. J Neurol Neurosurg Psychiatry 1996;60:403-10.

9 Rottach KG, Riley DE, DiScenna AO, et al. Dynamic properties of horizontal and vertical eye movements in parkinsonian syndromes. Ann Neurol 1996:39:368-77.

10 Leigh RJ, Zee DS. The neurology of eye movements, 3rd ed. New York: Oxford University Press, 1999:437.

11 Grant MP, Cohen M, Petersen RB, et al. Abnormal eye movements in Creutzfeld-Jakob disease. Ann Neurol 1993;34:192-7.

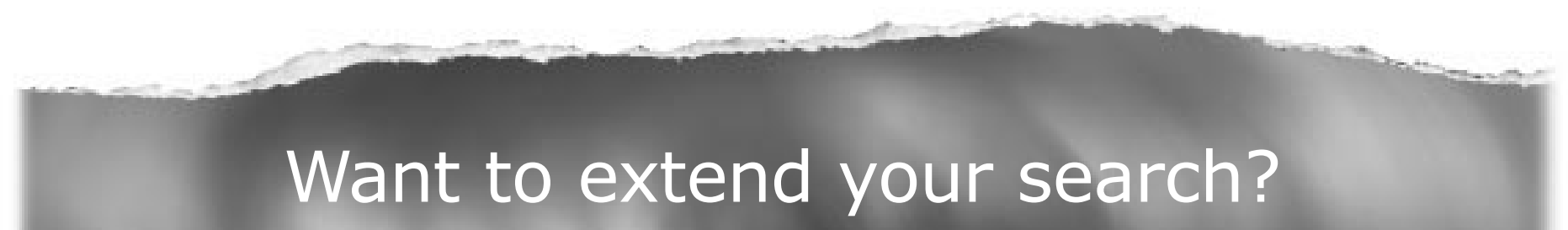

\section{Cross journal searching}

If you can't find what you are looking for in the Journal of Neurology, Neurosurgery, and Psychiatry you can extend your search across many of the more than 200 journals available for selection. You can restrict your search to specific subject areas (eg, clinical medicine, basic research), or select specific journals, or search all available titles.

\section{www.jnnp.com}

